\title{
Investigation of the Structures and Electronic Properties of 3'-(4-(5-Oxo-5- piperidin-1-yl)-penta-1,3-dienyl)benzo[d][1,3]dioxol-2-yl]Thymidine through DFT Calculations
}

\author{
A. H. Essa, M. A. N. Al-Magmoy ${ }^{*}$, and A. J. Hameed \\ Department of Chemistry, College of Science, University of Basrah, Basrah, Iraq \\ Received 1 November 2010, accepted in final revised form 9 January 2011
}

\begin{abstract}
The structural and electronic properties of 3'(4-(5-oxo-5-piperidin1-1-yl)penta-1,3dienyl)benzo[ $d][1,3]$ dioxol-2-yl]-thymidine molecule have been investigated theoretically by performing density functional theory (DFT/3-21G*, 6-31G* and 6-31G**). The geometry of the molecule is optimized, and the electronic properties and relative energies of the molecules have been calculated by density functional theory in the ground state. The resultant dipole moments of the studied molecule are about 5.5, 6.36 and 7.35 Debyes by three levels (3-21G*, 6-31G* and 6-31G**, respectively). This property makes it an active molecule with its environment that is this molecule may interacts with its environment strongly in solution.
\end{abstract}

Keywords: 3'-Azido-3'-deoxythymidine (AZT); Piperine; Density functional theory (DFT); Thymidine.

(c) 2011 JSR Publications. ISSN: 2070-0237 (Print); 2070-0245 (Online). All rights reserved.

doi:10.3329/jsr.v3i2.6364 J. Sci. Res. 3 (2), 339-345 (2011)

\section{Introduction}

Intensive efforts are underway worldwide to develop chemotherapeutic agents effective against HIV. Attempts are continuing to discover drugs that can interfere with a stage in the viral replicative cycle without damaging the normal processes of the host cell. Azidothymidine (AZT, Retrovir) [1] (1) is approved as an anti-HIV drug [2, 3] targeted as an effective inhibitor of the HIV reverse transcriptase enzyme [4]. However, this compound is not free from undesired side effects [5]. For this reason, different laboratories continue to synthesize new series of AZT analogues such as 5aminocarbonyl-phosphonyl and aminocarbonylmethylphosphonyl diesters [6], 5'alkylethoxy- and aminocarbonylphosphonates [7], amino acid carbamate derivatives [8],

\footnotetext{
* Corresponding author: almagmoy@gmail.com
} 
and amino acid phosphoramidate monoesters [9] in addition to several AZT analogues [10-12] to establish the structure-activity relationship for the AZT antiviral activity as well as its resistance to the HIV. The therapeutic (selectivity) index of some of these compounds exceeded that of the parent AZT due to their higher antiviral activity. HAART program (drugs combination) has taken a good opportunity to deal with the HIV problem, since many laboratories have some spectacular success by using a combined drugs with AZT. Several groups of researchers [13-18] had reported an extensive conformational analysis of AZT at the semi-empirical AM1 level with full relaxation of all geometric parameters and careful consideration of furan puckering and the rotational states of the thymine-furan, furan-azide, furan-methylene, and methylene-hydroxyl bonds. We report here the structural and electronic properties of our proposed derivative, 3'(4-(5-oxo-5piperidin1-1-yl)penta-1,3-dienyl)benzo[d][1,3]dioxol-2-yl]-thymidine (AHE), in case of the azide residue of AZT is replaced by a potentially active piperine group, for structural and activity comparison purposes.

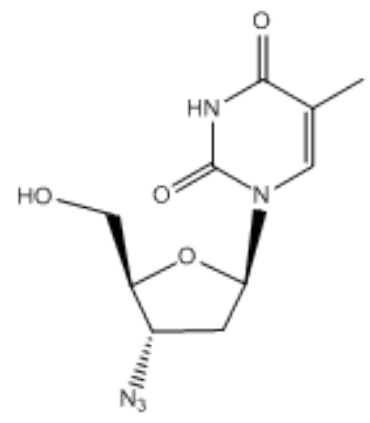

1. AZT

Piperine (5-(benzo[d][1,3]dioxol-5-yl)-1-(piperidin-1-yl)penta-2,4-dien-1-one) [19] is a naturally occurring product, isolated from ground black pepper, together with other alkaloids of piperidine, piperettine and piperanine [20]. Our study is the theoretical structural investigation for the proposed nucleoside, 3'-piperin-thymidine (AHE, 2), in comparison to the AZT, where the azide is replaced by the piperine congres. This study is performed at the three levels of density functional theory calculations method (3-21G*, 6$31 \mathrm{G}^{*}$ and $\left.6-31 \mathrm{G}^{* *}\right)$.

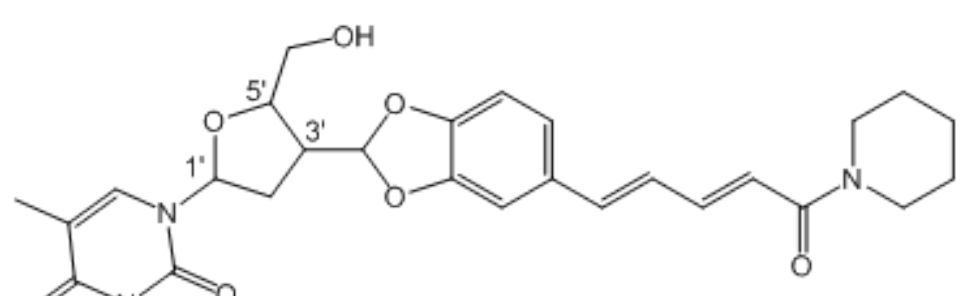

2. AHE molecule 


\section{Experimental}

The density functional theory (DFT) calculations were carried out with the GAUSSIAN03 suite of codes [21-25]. To perform such an analysis the B3LYP [26-28] method coupled to the $3-21 G^{*}, 6-31 G^{*}$ and $6-31 G^{* *}$ basis set were employed $[29,30]$. This method implements non-local correlation provided by the LYP expression, and VWN functional III for any local correlation. Also one must mention that LYP has both local and non-local terms, and the correlation functional can be described as:

$$
\mathrm{C}^{*} \mathrm{E}_{\mathrm{C}}^{\mathrm{LYP}}+(1-\mathrm{C}) * \mathrm{E}_{\mathrm{C}}^{\mathrm{VWN}}
$$

There by, VWN provides the excess local correlation required, because LYP contains a local term similar to VWN. Tight convergence criteria were used to verify that energies were in fact accurate. Additionally, the frequencies were evaluated to make sure that the structures were minimum energy species along the potential energy surface. The SCF convergence was set to $0.001 \mathrm{kcal} / \mathrm{mol}$ and the RMS gradient was set to $0.001 \mathrm{kcal} /(\AA$ mol) in the calculations.

\section{Results and Discussions}

Fig. 1 shows the optimized geometries of the AHE (a) 3-21G*, (b) 6-31G* (c) 6-31G** results. We find that the structural parameters of these levels are very similar.

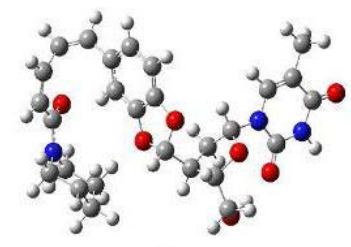

(a)

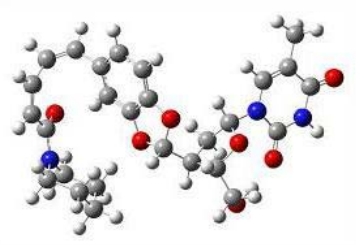

(b)

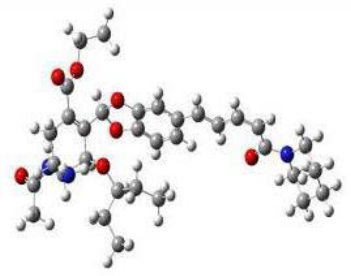

(c)
Fig. 1. The geometries for the AHE (a) 3-21G*, (b) 6-31G*, (c) 6-31G** results. (colour online) $\mathrm{O}, \mathrm{N}, \mathrm{C}$ and $\mathrm{H}$ are shown by red, blue, dark grey and grey balls, respectively. 
The calculated energies obtained by different levels (3-21G*, 6-31G* and 6-31G**) of the studied molecule as well as the highest occupied and the lowest unoccupied MO (HOMO and LUMO respectively) energies and the inter frontier MO energy gap (LUMO - HOMO energy difference, $\Delta E$ ) with the lowest and highest level energy values are also given in Table 1.

Table 1 . The total energy values, the MO energy of HOMO, LUMO levels, $\Delta E(\mathrm{eV})$, and dipole moment $\mu$ (Debyes) for AHE molecule that calculated by three DFT levels.

\begin{tabular}{cccc}
\hline \multirow{2}{*}{ Quantity } & \multicolumn{3}{c}{ DFT } \\
\cline { 2 - 4 } & B3LYB/3-21G* & B3LYB/6-31G* & B3LYB/6-31G** \\
\hline Total energy & -29520885.22 & -47305.86 & -53757.23 \\
HOMO & -8.2179 & -6.0728 & -5.6614 \\
LUMO & -5.3334 & -1.6506 & -2.0844 \\
$\Delta E$ & 2.8844 & 4.422 & 3.5770 \\
$\mu$ & 5.5 & 6.36 & 7.35 \\
\hline
\end{tabular}

The resultant dipole moments of the AHE molecule (Table 1) are about 5.5, 6.36 and 7.35 Debyes by three levels (3-21G*, 6-31 $\mathrm{G}^{*}$ and 6-31 $\mathrm{G}^{* *}$ ) respectively. It can be speculated that the change of dipole moment is firstly due to the component and nature of optimized geometries in these three levels, rather than the electron density redistribution over the central fragment. The AHE which has a greater dipole moment will be more stable in polar solvents. This property of AHE makes it an active molecule with its environment, therefore the AHE molecule may interact with its environment strongly in solution.

The molecular orbital surfaces of the HOMO and LUMO for AHE presented in Fig. 2 showed that the contour plots of HOMO and LUMO of AHE in three levels are similar. The electron density of HOMO is concentrated on the dioxolane and benzene ring of the parent AHE. As for the LUMO, the electron density distribution is mainly localized on the $\mathrm{C}-\mathrm{C}$ axis of the conjugated system. So the electronic transition from HOMO to LUMO could lead to a big geometrical relaxation about the C-C bond. On the other hand, the electronic transition from HOMO to LUMO could lead to the intramolecular charge transfer from benzodioxole to the parent AHE. The electronic character is also of interest with respect to its reactivity, especially towards nucleophilic agents. Isosarface of the electrostatic potential (ESP) of molecule illustrated that oxygen and nitrogen atoms have more negative ESP regions in comparison to other atoms, which means that both oxygen and nitrogen atoms undergo protonation reaction with acidic reagents [31, 32]. 


\section{Conclusion}

The structural and electronic properties of our proposed derivative, 3'(4-(5-oxo-5piperidin1-1-yl)penta-1,3-dienyl)benzo[d][1,3]dioxol-2-yl]-thymidine (AHE), in case of the azide residue of AZT is replaced by a potentially active piperine group, are reported here for structural and activity comparison purposes. Our study here is the theoretical structural investigation for the proposed nucleoside, 3'-piperin-thymidine (AHE, 2), in comparison to the AZT, where the azide is replaced by the piperine congres. This study is performed at three levels of density functional theory calculations method (3-21G*, 6$31 \mathrm{G}^{*}$ and $6-31 \mathrm{G}^{* *}$ ). It can be speculated that the change of dipole moment is firstly due to the component and nature of optimized geometries in these three levels, rather than the electron density redistribution over the central fragment. The AHE which has a greater dipole moment will be more stable in polar solvents. This property of AHE makes it an active molecule with its environment, therefore the AHE molecule may interact with its environment strongly in solution.

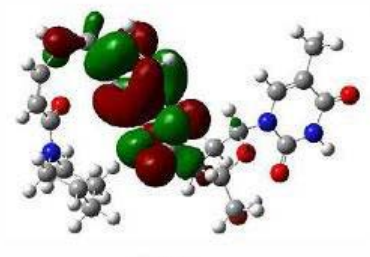

HOMO

(a)

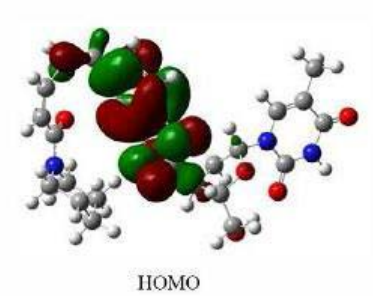

(b)

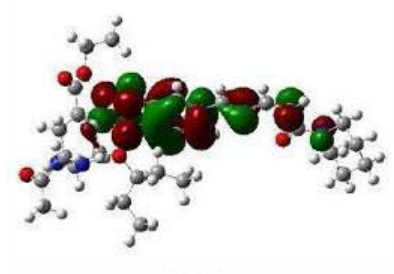

HOMO

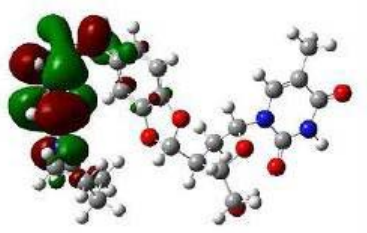

LUMO

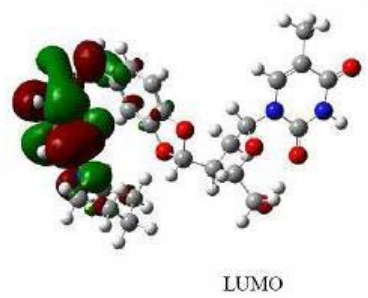

LUMO

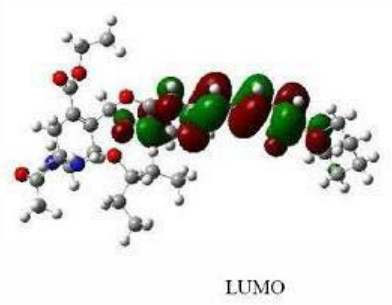

LUMO

(C)

Fig. 2. Molecular orbital surfaces of the HOMO and LUMO for the ground-state of the studied molecule (a) 3-21G*, (b) 6-31G*, (c) 6-31G** results. (colour online) O, N, C and H are shown by red, blue, dark grey and grey balls, respectively. 


\section{Acknowledgment}

We wish to express thanks to Professor N. Al-Masoudi of Konstanz University, Germany to read the draft, and kindly put his valuable comments before the submission.

\section{References}

1. H. Mitsuya, K. J. Weinhold, P. A. Furman, M. H. Clair, S. N. Lehrmann, R. C. Gallo, D. Bolognesi, D. W. Barry, and S. Broder, Proc. Natl. Acad. Sci. 82, 7096 (1985). doi:10.1073/pnas.82.20.7096

2. P. A. Furman, J. A. Fyfe, M. H. St Clair, K. Weinhold, J. L. Rideout, G. A. Freeman, S. N. Lehrman, D. P. Bolognesi, S. Broder, and H. Mitsuya, PNAS 83, 8333 (1986). doi:10.1073/pnas.83.21.8333

3. E. De Celercq, Expert Opinion on Emerging Drugs 10, 241 (2005). doi:10.1517/14728214.10.2.241

4. H. Jonckeere, J. Ann'e, and E. De Clercq, Med. Res. Rev. 20, 129 (2000). doi:10.1002/(SICI)1098-1128(200003)20:2<129::AID-MED2>3.0.CO;2-A

5. E. Sandstrom and B. Oberg, Drug. 45, 488 (1993). doi:10.2165/00003495-199345040-00002

6. E. A. Shirokova, M. V. Jasko, A. L. Khandazhinskaya, D. V. Yanvarev, Y. S. Skoblov, T. R. Pronayeva, N. V. Fedyuk, A. G. Pokrovsky, and M. K. Kukhanova, Nucleosides. Nucleotides . Nucleic Acids 22, 981 (2003). doi:10.1081/NCN-120022718

7. E. A. Shirokova, M. V. Jasko, A. L. Khandazhinskaya, A. V. Ivanov, D. V. Yanvarev, Y. S. Skoblov, V.A. Mitkevich, E.V. Bocharov, T.R. Pronyaeva, N.V. Fedyuk, and M. K. Kukhanova, J. Med. Chem. 47, 3606 (2004). doi:10.1021/jm0310176

8. S.L. Chang, G. Griesgraber, T.W. Abraham, T. Garg, H. Song, C.L. Zimmerman, and C.R. Wagner, Nucleosides. Nucleotides. Nucleic Acids 19, 87 (2000). doi:10.1080/15257770008032998

9. S. Chang, G. W. Griesgraber, P. J. Southern, and C. R. Wagner, J. Med. Chem. 44, 223 (2001). doi:10.1021/jm000260r

10. D. R. Adams, C. Perez, M. Maillard, J. C. Florent, M. Evers, Y. He'́nin, S. Litvak, L. Litvak, C. Monneret, and D. S. Grierson, J. Med. Chem. 40, 1550 (1997). doi:10.1021/jm9600095

11. P. Vlieghe, T. Clerc, C. Pannecouque, M. Witvrouw, E. De Clercq, J. P. Salles, and J. K. Kraus, J. Med. Chem. 44, 3014 (2001). doi:10.1021/jm010863i

12. S. Chang, W. George, W. Griesgraber, P. J. Southern , and C. R. Wagner, J. Med. Chem. 44, 223 (2001). doi:10.1021/jm000260r

13. A. S. Ray, E. Murakami, A. Basavapathruni, A. J. Vaccaro, D. Ulrich, C. K. Chu, R.F. Schinazi, and K.S. Anderson, Biochemistry 42, 8831 (2003). doi:10.1021/bi034435l

14. M. Ait-Khaled, A. Rakik, P. Griffin, A. Cutrell, M. A. Fischl, N. Clumeck, S. B. Greenberg, R. Rubio, B. S. Peters, F. Pulido, J. Gould, G. Pearce, W. Spreen, M. Tisdale, and S. Lafon, Antivir. Ther. 7, 43 (2002).

15. C. Allavena, V. Ferre', J. F. Delfraissy, A. Lafeuillade, M. A.Valantin, M. Bentata, C. Michelet, I. Poizot-Martin, E. Dailly, O. Launay, and F. Raffi, J. Aids 39, 300 (2005). doi:10.1097/01.qai.0000165914.42827.bb

16. E. DeJesus, G. Herrera, E. Teofilo, J. Gerstoft, C. B. Buendia, J. D. Brand, C. H. Brothers, J. Hernandez, S. A. Castillo, T. Bonny, and E. R. Lanier, Clin. Infect. Dis. 39, 1038 (2004). doi:10.1086/424009

17. N. Paton, S. Sangeetha, A. Earnest, and R. Bellamy, HIV Medicine 7, 323 (2006). doi:10.1111/j.1468-1293.2006.00383.x

18. M. Sabio and S. Topiol, J. Comput. Chem. 13, 478 (1991). doi:10.1002/jcc.540130410

19. W. W. Epstein, D. F. Netz, and J. L. Seidel, J. Chem. Ed. 70, 598 (1993). doi:10.1021/ed070p598 
20. R. Ikan, Natural Products: A Laboratory Guide, $2^{\text {nd }}$ edition (Academic Press, New York, 1991) pp. 55-60.

21. M. J. S. Dewar, E. G. Zoebisch, E. F. Healy, and J. J. P. Stewart, J. Am. Chem. Soc. 107, 3902 (1985). doi:10.1021/ja00299a024

22. C. C. J. Roothaan, Rev. Mod. Phys. 23, 69 (1951). doi:10.1103/RevModPhys.23.69

23. P. Fletcher, Practical Methods of Optimization (Wiley, New York, 1990) pp. 144-150.

24. W. Kohn and L. Sham, J. Phys. Rev. 140, A1133 (1965). doi:10.1103/PhysRev.140.A1133

25. M. J. Frisch, G. W. Trucks, H. B. Schlegel, G. E. Scuseria, M. A. Robb, J. R. Cheeseman, J. A. Montgomery, Jr., T. Vreven, K. N. Kudin, J. C. Burant, J. M. Millam, S. S. Iyengar, J. Tomasi, V. Barone, B. Mennucci, M. Cossi, G. Scalmani, N. Rega, G. A. Petersson, H. Nakatsuji, M. Hada, M. Ehara, K. Toyota, R. Fukuda, J. Hasegawa, M. Ishida, T. Nakajima, Y. Honda, O. Kitao, H. Nakai, M . Klene, X. Li, J. E. Knox, H. P. Hratchian, J. B. Cross, V. Bakken, C. Adamo, J. Jaramillo, R. Gomperts, R. E. Stratmann, O. Yazyev, A. J. Austin, R. Cammi, C. Pomelli, J. W. Ochterski, P. Y. Ayala, K. Morokuma, G. A. Voth, P. Salvador, J. J. Dannenberg, V. G. Zakrzewski, S. Dapprich, A. D. Daniels, M. C. Strain, O. Farkas, D. K. Malick, A. D. Rabuck, K. Raghavachari, J. B. Foresman, J. V. Ortiz, Q. Cui, A. G. Baboul, S. Clifford, J. Cioslowski, B. B. Stefanov, G. Liu, A. Liashenko, P. Piskorz, I. Komaromi, R. L. Martin, D. J. Fox, T. Keith, M. A. Al-Laham, C. Y. Peng, A. Nanayakkara, M. Challacombe, P. M. W. Gill, B. Johnson, W. Chen, M. W. Wong, C. Gonzalez, and J. A. Pople, Gaussian 03, Revision C.02 (Gaussian, Inc. Wallingford CT, 2004).

26. J. S. Binkley, J. A. Pople, and W. J. Hehre, J. Am. Chem. Soc. 102, 939 (1980). doi:10.1021/ja00523a008

27. A. D. Becke, J. Chem. Phys. 98, 5648 (1993). doi:10.1063/1.464913

28. C. Lee, W. Yang, and R. G. Parr, Phys. Rev. B 37, 785 (1988). doi:10.1103/PhysRevB.37.785

29. A. D. Becke, J. Chem. Phys. 98, 5648 (1993). doi:10.1063/1.464913

30. A. O. Calvi, L. A. Montero, and W. D. Stohrer, J. Mol. Struct. Theochem. 859, 93 (2008). doi:10.1016/j.theochem.2008.03.006

31. A. J. Hameed, J. Mol. Struct. Theochem. 728, 43 (2005). doi:10.1016/j.theochem.2005.04.035

32. S. Erkoc, M. Yilmazer, and F. Erkoc, J. Mol. Struct. Theochem. 583, 169 (2002). doi:10.1016/S0166-1280(01)00799-0 